\title{
24-h urinary sodium excretion is associated with obesity in a cross-sectional sample of Australian schoolchildren
}

\author{
Carley A. Grimes ${ }^{1 *}$, Lynn J. Riddell ${ }^{1}$, Karen J. Campbell ${ }^{1}$, Feng J. He ${ }^{2}$ and Caryl A. Nowson ${ }^{1}$ \\ ${ }^{1}$ School of Exercise and Nutrition Sciences, Centre for Physical Activity and Nutrition Research, Deakin University, Burwood, \\ VIC 3125, Australia \\ ${ }^{2}$ Centre for Environmental and Preventative Medicine, Wolfson Institute of Preventative Medicine, Queen Mary University of \\ London, London EC1M 6BQ, UK
}

(Submitted 24 August 2015 - Final revision received 2 December 2015 - Accepted 3 December 2015 - First published online 26 January 2016)

\section{Abstract}

Emerging evidence indicates that dietary Na may be linked to obesity; however it is unclear whether this relationship is independent of energy intake (EI). The aim of this study was to assess the association between Na intake and measures of adiposity, including BMI $z$ score, weight category and waist:height ratio (WHtR), in a sample of Australian schoolchildren. This was a cross-sectional study of schoolchildren aged 4-12 years. Na intake was assessed via one 24-h urine collection. BMI was converted to age- and sex-specific $z$ scores, and WHtR was used to define abdominal obesity. In children aged $\geq 8$ years, EI was determined via one 24-h dietary recall. Of the 666 children with valid urine samples $55 \%$ were male (average age 9.3 (sD 1.8) years). In adjusted models an additional $17 \mathrm{mmol} / \mathrm{d}$ of $\mathrm{Na}$ was associated with a $0 \cdot 10$ higher BMI $z$ score (95\% CI 0.07, 0.13), a 23\% (OR 1.23; $95 \%$ CI 1.16, 1.31) greater risk of being overweight/obese and a 15\% (OR 1.15; $95 \%$ CI 1.09, 1.23) greater risk of being centrally obese. In the subsample of 8-12-year-old children ( $n$ 458), adjustment for EI did not markedly alter the associations between $\mathrm{Na}$ and adiposity outcomes. Using a robust measure of daily $\mathrm{Na}$ intake we found a positive association between $\mathrm{Na}$ intake and obesity risk in Australian schoolchildren, which could not be explained by total energy consumption. To determine whether this is a causal relationship, longitudinal studies, with high-quality measures of $\mathrm{Na}$ and EI, are required.

\section{Key words: Sodium, dietary: Sodium chloride, dietary: Obesity: Adiposity: Children: Australia}

In developed countries most children consume too much $\mathrm{Na}$ with intakes frequently exceeding dietary recommendations ${ }^{(1)}$. In addition to the more well-established links between $\mathrm{Na}$ intake and blood pressure ${ }^{(2)}$, $\mathrm{Na}$ has recently been associated with obesity risk in children and adolescents ${ }^{(3-8)}$. Early work in this area focused on the indirect association of $\mathrm{Na}$ intake with obesity through the greater consumption of sugar-sweetened beverages $(\mathrm{SSB})^{(3-5,9)}$, which are a known risk factor for weight gain in children ${ }^{(10)}$. Across these population-based cross-sectional studies $\mathrm{Na}$ intake was found to be positively associated with total fluid intake as well as SSB intake in children and adolescents from the $\mathrm{UK}^{(5)}$, the $\mathrm{USA}^{(4)}$ and Australia ${ }^{(3)}$. Informed by experimental evidence in animals $^{(11)}$ and adults ${ }^{(12,13)}$, which shows the activation of thirst and fluid intake to regulate body fluid balance when $\mathrm{Na}$ intake is increased, the observed association between $\mathrm{Na}$ and SSB intake in children is plausible.

However, in contrast to these findings, other studies have reported positive associations between $\mathrm{Na}$ intake and measures of adiposity independent of energy intake $(\mathrm{EI})^{(6-8)}$. In Korean children $\mathrm{Na}$ density ( $\mathrm{Na}$ intake (mg)/food intake (g) per d) was positively associated with obesity and abdominal obesity ${ }^{(7)}$, and in US adolescents ${ }^{(8)} \mathrm{Na}$ intake was positively associated with $\mathrm{BMI}$, waist circumference and percentage of body fat (\%BF), independent of energy and SSB intake. In all of the aforementioned studies $\mathrm{Na}$ intake was assessed using dietary recall or food diary methods. These methods do not measure the amount of $\mathrm{Na}$ from table or cooking salt and therefore tend to underestimate total daily $\mathrm{Na}$ intake ${ }^{(14)}$. To date, only one paediatric study has used 24-h urinary $\mathrm{Na}$ excretion to assess the relationship between total daily $\mathrm{Na}$ (i.e. food sources and discretionary salt) intake and obesity risk ${ }^{(6)}$. In this study of German children 24-h urinary Na excretion was positively associated with BMI $z$ score and \%BF. Furthermore, the association remained after the adjustment of total EI or SSB intake. Overall, there is a growing evidence base to indicate that $\mathrm{Na}$ intake is associated with measures of adiposity in children. However, there is limited evidence using a reliable measure of total daily $\mathrm{Na}$ intake. Given the tracking phenomenon of overweight and obesity from childhood across the lifespan ${ }^{(15)}$, understanding dietary determinants of obesity is of paramount importance. Hence, the aim of this study was to assess the association between total daily $\mathrm{Na}$ intake, as assessed by $24-\mathrm{h}$

Abbreviations: \%BF, percentage of body fat; EI, energy intake; SES, socio-economic status; SSB, sugar-sweetened beverages.

* Corresponding author: C. A. Grimes, email carley.grimes@deakin.edu.au 
urinary $\mathrm{Na}$ excretion, and measures of adiposity, including BMI $z$ score, weight category and abdominal obesity, in a sample of Australian schoolchildren aged 4-12 years.

\section{Methods}

Data for this analysis come from the cross-sectional Salt and Other Nutrient Intakes in Children study, and the methods ${ }^{(16)}$ have been reported previously.

Study invitations were sent to a convenience sample of 509 government and non-government schools, and fifty-six schools (11\%) agreed to participate. Within participating schools consent was obtained from 852 children (response rate $=6 \%$ ); forty-one children withdrew from the study and children who did not agree to attend an off-school campus data collection day ( $n$ 25) or who were aged $>13$ years ( $n$ 6) were excluded, leaving 780 participants. The Deakin University Research Ethics Committee (Project No: EC 62-2009) approved the study. Written informed consent was obtained from the primary caregiver and the child.

\section{Measures}

Data collection occurred between June 2010 and May 2013. Parents completed a questionnaire reporting on children's date of birth and sex. Socio-Economic Indexes for Areas, Index of Relative Socio-Economic Disadvantage ${ }^{(17)}$, was used to group schools, based on school postcode, into tertiles of socio-economic disadvantage. This marker was used to define socio-economic status (SES), whereby the participant was grouped as either low, mid or high SES with reference to the tertile that the school they attended fell within.

\section{4-h urine collection}

Details of the 24-h urine collection procedures have been previously described $^{(16)}$. In brief, children could opt to commence the 24-h urine collection at the start of a school day (i.e. approximately 09.00 hours Monday to Friday) or at any suitable time on a non-school day (i.e. weekends, public holidays and school holidays). At the commencement of the 24-h urine collection, children were instructed to empty their bladder, discard this urine and note this as the start time. Following this, all urine voided was collected up until the corresponding 24-h finish time. Parents and children were provided with written instructions on how to complete the 24-h urine collection. Parents were asked to report any missed collections or spillages on a urine collection slip, which was returned with the 24-h urine sample. Returned 24-h urine samples were transported to an accredited commercial pathology laboratory (Dorevitch Pathology) for urinalysis. Urinary $\mathrm{Na}$ and $\mathrm{K}$ concentration was assessed using indirect ion selective electrodes, and urinary creatinine concentration was assessed using the Jaffe reaction $^{(18)}$ on the Siemens Advia 2400 analyser (Siemens Healthcare). The $\mathrm{CV}$ for $\mathrm{Na}$ and $\mathrm{K}$ was $<1 \%$ and for creatinine it was $3.25 \%$. The molecular weights of $\mathrm{Na}(23 \mathrm{~g} / \mathrm{mol})$ and sodium chloride $(58.5 \mathrm{~g} / \mathrm{mol})$ were used to convert laboratory values in mmol of $\mathrm{Na}$ to $\mathrm{mg}^{(19)}$. If the duration of the collection was not exactly $24 \mathrm{~h}$ but within $20-28 \mathrm{~h}$, urinary electrolytes, creatinine and total volume were standardised to a 24 -h period (i.e. (24h/urine duration (h) $\times$ urinary measure). Urine samples were considered incomplete if collection time was $<20$ or $>28 \mathrm{~h}$, total volume was $<300 \mathrm{ml}$, the participant reported missing $>1$ collection, or urinary creatinine excretion was $<0.1 \mathrm{mmol} / \mathrm{kg}$ body weight per $\mathrm{d}^{(16)}$. Of the 780 participants, 763 returned urine specimens and 667 of these were deemed complete ${ }^{(16)}$. One extreme outlier for urinary $\mathrm{Na}$ excretion (mean 531 (SD 8.7) mmol) was excluded, leaving an analytical sample of 666 . There were no differences in age, sex, SES or weight category between completers and non-completers of the urine collection.

\section{Anthropometric measurements}

Height, weight and waist circumference were measured by trained research staff following standard protocols ${ }^{(16)}$. BMI values were converted to age- and sex-adjusted BMI $z$ scores using the 2000 US Centers for Disease Control and Prevention growth charts $^{(20,21)}$. Participants were grouped into weight categories (underweight, healthy weight, overweight, obese) using the International Obesity Taskforce BMI reference cut-offs for children $^{(22,23)}$. The waist:height ratio (WHtR), which is not dependent on age or sex references, was used as a marker of central adiposity ${ }^{(24)}$. This was calculated as waist circumference $(\mathrm{cm})$ divided by height $(\mathrm{cm})$. A WHtR $\geq 0.5$ has been associated with cardiovascular risk factors in the paediatric population ${ }^{(24,25)}$, and this cut-off was used to define abdominal obesity ${ }^{(24)}$.

\section{Dietary intake}

One face-to-face three-pass 24-h dietary recall was completed with the child on the day of the testing procedures completed at the school site. This method includes the following stages: (i) provide a quick list of all foods and beverages consumed from midnight to midnight on the day before the interview; (ii) probe questions relevant to each quick list item to gather more detailed information - for example, the amount consumed, brand name, additions to the food item; and (iii) a recall review to cross-check information. In this analysis we report intakes of energy $(\mathrm{MJ} / \mathrm{d})$ and SSB $(\mathrm{g} / \mathrm{d})$ in the subsample of children aged $\geq 8$ years who completed a three-pass 24 -h dietary recall. Of these 498 children, six could not complete the dietary recall and were excluded from the analysis. Children $<8$ years of age do not reliably recall food ${ }^{(26)}$ intakes and dietary data are not presented for this age group ( $n$ 168). SSB included sugar-sweetened soda, cordial, fruit drinks, flavoured mineral water, and sports and energy drinks ${ }^{(3)}$.

The paediatric adjusted Goldberg cut-off method ${ }^{(27)}$ was used to identify participants with implausible EI. This method compares the participant's ratio of reported EI:estimated BMR (estBMR) with the Goldberg cut-off 2 value. Age- and sex-specific Goldberg cut-off values were determined using the original adult Goldberg equation ${ }^{(28)}$, substituted with child-specific light physical activity levels (PAL) ${ }^{(29)}$ and revised estimates ${ }^{(30)}$ for the $\mathrm{CV}$ in $\mathrm{EI}\left(\mathrm{CV}_{\mathrm{wEI}} 23 \%\right)$, repeated BMR measurements $\left(\mathrm{CV}_{\mathrm{wB}} 8.5 \%\right)$ and variation in PAL $\left(\mathrm{CV}_{\text {tp }} 15 \%\right)$. On this basis, participants ( $n 34$, $6.9 \%$ ) with an EI:estBMR ratio $<0.87$ for $8-12$-year-old boys and 0.84 for 8-12-year-old girls were classified as a low-energy reporter and excluded from analyses with dietary data. It has been 
shown that under-reporting is more likely to occur with increased body fatness ${ }^{(31)}$. Therefore, in this analysis, which includes adiposity as an outcome measure, we considered it important to identify and exclude low-energy reporters. An additional sensitivity analysis was performed, whereby no children were excluded on the basis of misreporting. In this analysis there was no appreciable change to the results when identified low-energy reporters were included (data not shown).

Logistically it was not possible to concurrently collect 24-h dietary recalls alongside the 24-h urine collection. Instead 24-h recalls were collected with children on the day of testing procedures completed at the school site (i.e. actual recalled food intake is for the day before testing procedures), whereas children could opt to commence the 24-h urine collection at school on the day of testing, or over a weekend day. Overall, 416 (91\%) children completed the 24-h dietary recall and 24-h urine collection within a week of one another. In some instances, because of the child being unwell on the day of testing or away for an extended holiday period the timing between the 24-h dietary recall and 24-h urine collection was greater than a week (i.e. $n 29,7 \%$ collected within a 2 -week period, and $n 14,3 \%$ collected within a 6 -week period).

\section{Statistical analysis}

Descriptive statistics (mean values and standard deviations or proportions and numbers) were used to describe participant characteristics. Because SSB (g/d) intake was skewed, medians and interquartile ranges were reported. Multiple linear regression was used to assess the association between urinary $\mathrm{Na}$ excretion $(17 \mathrm{mmol} / \mathrm{d}$, equivalent to $1 \mathrm{~g} / \mathrm{d}$ of salt) and BMI $z$ score. Logistic regression was used to assess the association between 24-h urinary $\mathrm{Na}$ excretion $(17 \mathrm{mmol} / \mathrm{d})$ and (i) weight category and (ii) abdominal obesity. The unadjusted and adjusted models (age, sex and SES) are presented. Where abdominal obesity was the outcome, additional adjustment for BMI $z$ score was made. To assess whether the association between 24-h urinary $\mathrm{Na}$ excretion and adiposity outcome measures was independent of energy and SSB intake, additional models were constructed with these covariates. In this analysis EI was adjusted using the standard multivariable method, as opposed to the residual method, as there was no collinearity between 24-h urinary $\mathrm{Na}$ and EI $(r$ 0.10, $P=0.03)$. One outlier with an implausible waist circumference (i.e. $32 \mathrm{~cm}$, which was $3.5 \mathrm{sD}$ away from the mean waist circumference), was removed from the analyses related to WHtR. The normality of regression residual distributions was visually assessed and linearity checked using a component-plus-residual plot. To account for clustering of students within schools, clustered robust standard errors were used. Of note, the intra-class correlation (ICC) for the exposure variable (i.e. Na excretion) was 0.024 and the ICC for the primary outcome variable (i.e. BMI $z$ score) was 0.030. Analyses were completed with STATA/SE 13.0 software (StataCorp LP), and a $P$ value $<0.05$ was considered statistically significant

\section{Results}

Table 1 shows the demographic characteristics of participants and information on urinary excretion and dietary intake.
Table 1. Descriptive characteristics of participants (Mean values and standard deviations; or numbers and percentages)

\begin{tabular}{|c|c|c|c|c|c|c|}
\hline \multirow[b]{2}{*}{ Characteristics } & \multicolumn{2}{|c|}{ All participants } & \multicolumn{2}{|c|}{$4-7$ years } & \multicolumn{2}{|c|}{$8-12$ years } \\
\hline & Mean & SD & Mean & SD & Mean & SD \\
\hline \multicolumn{7}{|l|}{ Participants } \\
\hline$n$ & \multirow{2}{*}{\multicolumn{2}{|c|}{666}} & \multirow{2}{*}{\multicolumn{2}{|c|}{$\begin{array}{l}168 \\
25 \cdot 2\end{array}$}} & \multirow{2}{*}{\multicolumn{2}{|c|}{498}} \\
\hline$\%$ & & & & & & \\
\hline Age (years) & $9 \cdot 3$ & $1 \cdot 8$ & $6 \cdot 9$ & 0.7 & $10 \cdot 1$ & $1 \cdot 2$ \\
\hline \multicolumn{7}{|l|}{ Male } \\
\hline$n$ & \multicolumn{2}{|c|}{365} & \multicolumn{2}{|c|}{96} & \multicolumn{2}{|c|}{269} \\
\hline$\%$ & \multicolumn{2}{|c|}{54.8} & \multicolumn{2}{|c|}{$57 \cdot 1$} & \multicolumn{2}{|c|}{54.0} \\
\hline \multirow{2}{*}{\multicolumn{7}{|c|}{$\begin{array}{l}\text { Socio-economic } \\
\text { status } \\
\text { Bottom tertile }\end{array}$}} \\
\hline & & & & & & \\
\hline$n$ & \multirow{2}{*}{\multicolumn{2}{|c|}{$\begin{array}{c}108 \\
16 \cdot 2\end{array}$}} & \multicolumn{2}{|c|}{22} & \multicolumn{2}{|c|}{86} \\
\hline$\%$ & & & & $3 \cdot 1$ & & 3 \\
\hline Mid tertile & & & & & & \\
\hline$n$ & 14 & 48 & 5 & & 9 & \\
\hline$\%$ & & $22 \cdot 2$ & & .4 & & .5 \\
\hline Top tertile & & & & & & \\
\hline$n$ & 4 & 10 & 9 & & 31 & \\
\hline$\%$ & & $51 \cdot 6$ & & 6.5 & & $3 \cdot 2$ \\
\hline Height (cm) & $137 \cdot 8$ & $11 \cdot 3$ & $125 \cdot 3$ & $6 \cdot 4$ & $142 \cdot 0$ & $9 \cdot 3$ \\
\hline BMI $\left(\mathrm{kg} / \mathrm{m}^{2}\right)$ & $17 \cdot 3$ & 2.9 & $15 \cdot 7$ & $2 \cdot 0$ & $17 \cdot 9$ & $2 \cdot 9$ \\
\hline BMI $z$ score & 0.10 & 1.05 & -0.19 & 1.2 & 0.20 & 1.00 \\
\hline Weight category & & & & & & \\
\hline Underweight & & & & & & \\
\hline$n$ & & 67 & 3 & & 3 & \\
\hline$\%$ & & $0 \cdot 1$ & & 3.5 & & $\cdot 2$ \\
\hline Healthy weight & & & & & & \\
\hline$n$ & $4 \varepsilon$ & 37 & 12 & & 36 & \\
\hline$\%$ & & $73 \cdot 1$ & & 3.2 & & 1 \\
\hline Overweight & & & & & & \\
\hline$n$ & & 92 & 1 & & 8 & \\
\hline$\%$ & & 13.8 & & 9 & & .5 \\
\hline Obese & & & & & & \\
\hline$n$ & & 20 & 4 & & 1 & \\
\hline$\%$ & & 3.0 & & 4 & & $\cdot 2$ \\
\hline $\begin{array}{l}\text { Waist circumference } \\
(\mathrm{cm})\end{array}$ & $64 \cdot 3$ & 9.0 & $58 \cdot 1$ & 5.4 & $66 \cdot 3$ & $9 \cdot 1$ \\
\hline $\mathrm{WH} \mathrm{tR}$ & 0.47 & 0.05 & 0.46 & 0.04 & 0.47 & 0.05 \\
\hline $\mathrm{WHtR} \geq 0.5^{*}$ & & & & & & \\
\hline$n$ & $1<$ & 43 & 2 & & 11 & \\
\hline$\%$ & & 21.5 & & $4 \cdot 3$ & & 9 \\
\hline Day of urine collection & & & & & & \\
\hline School day & & & & & & \\
\hline$n$ & 3 & 17 & 7 & & 24 & \\
\hline$\%$ & & $47 \cdot 6$ & & 2.9 & & 2 \\
\hline Non-school day & & & & & & \\
\hline$n$ & 3 & 49 & 9 & & 25 & \\
\hline$\%$ & & 52.4 & & $7 \cdot 1$ & & 8 \\
\hline $\mathrm{Na}$ intake $(\mathrm{mmol} / \mathrm{d})$ & 103.4 & $45 \cdot 0$ & $87 \cdot 4$ & $36 \cdot 2$ & $108 \cdot 8$ & $46 \cdot 4$ \\
\hline Na intake (mg/d) & 2378 & 1034 & 2011 & 833 & 2503 & 1066 \\
\hline Salt equivalent $(\mathrm{g} / \mathrm{d})$ & 6.05 & $2 \cdot 63$ & $5 \cdot 11$ & $2 \cdot 12$ & $6 \cdot 36$ & $2 \cdot 71$ \\
\hline $\mathrm{K}$ intake $(\mathrm{mmol} / \mathrm{d})$ & $46 \cdot 6$ & $18 \cdot 1$ & 39.3 & $14 \cdot 1$ & $49 \cdot 0$ & 18.6 \\
\hline $\mathrm{Na} \mathrm{K}$ (molar ratio) & $2 \cdot 39$ & 1.06 & $2 \cdot 41$ & $1 \cdot 14$ & $2 \cdot 38$ & 1.03 \\
\hline $\begin{array}{l}\text { Creatinine excretion } \\
(\mathrm{mmol} / \mathrm{d})\end{array}$ & $5 \cdot 6$ & $2 \cdot 0$ & 3.4 & $1 \cdot 2$ & $6 \cdot 1$ & $2 \cdot 0$ \\
\hline Volume output (ml/d) & 866 & 416 & 722 & 300 & 915 & 438 \\
\hline
\end{tabular}

$\mathrm{WHtR}$, waist:height ratio

* One additional outlier for waist circumference removed from analyses.

An overall $55 \%$ were male, $62 \%$ were of high socio-economic background, and the average age was 9.3 years. In total, $17 \%$ of children were either overweight or obese and just under a quarter were classified as centrally obese. $\mathrm{Na}$ intake was $2378 \mathrm{mg} / \mathrm{d}$ and intakes were higher in older children.

Table 2 shows anthropometric measures and key characteristics by tertile of 24-h urinary $\mathrm{Na}$ excretion. BMI $z$ score and waist circumference increased with increasing intakes of $\mathrm{Na}$, as did the proportion of children who were overweight or obese. 
C. A. Grimes et al.

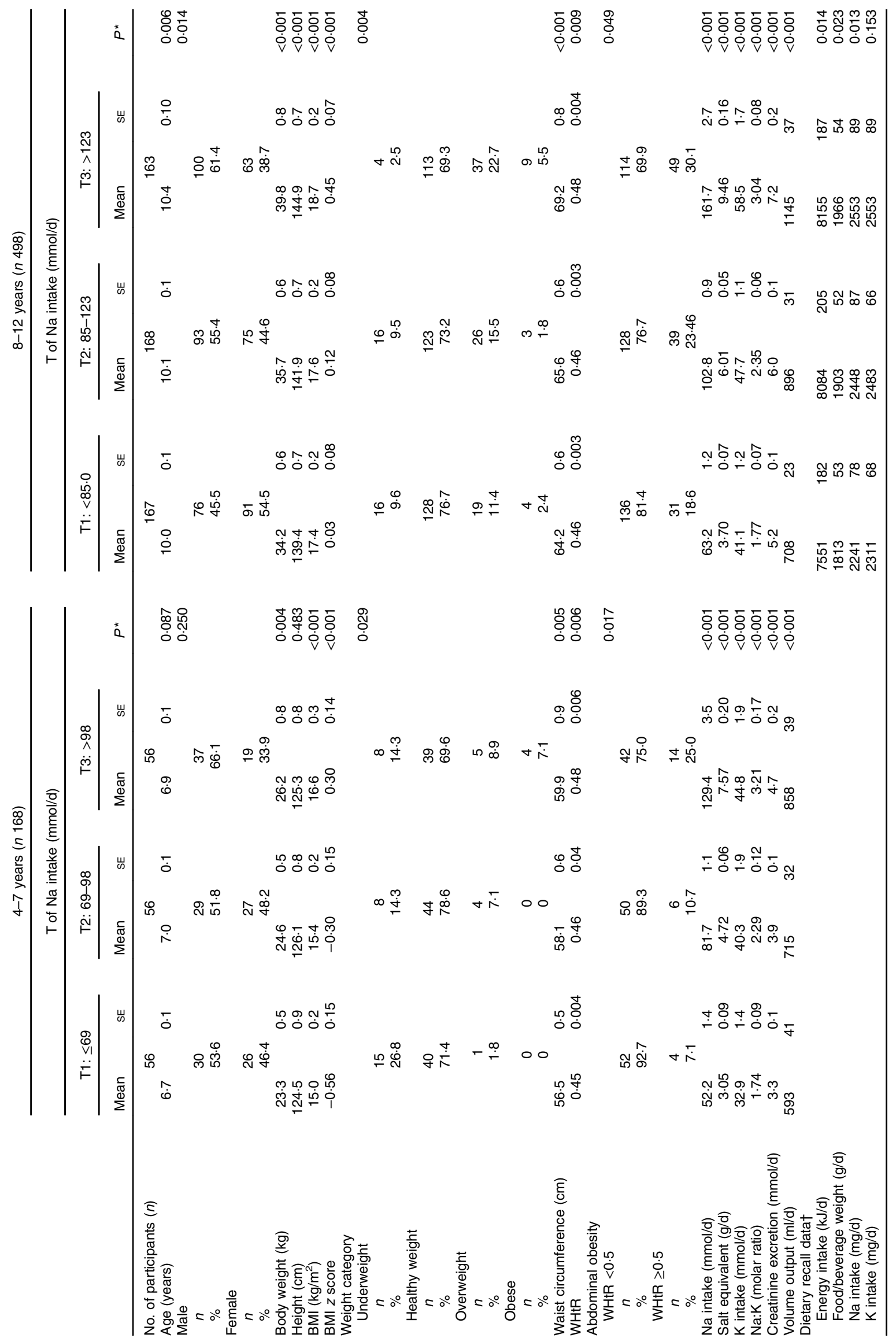


In both 4-7-year olds and 8-12-year olds the prevalence of abdominal obesity increased with higher intakes of $\mathrm{Na}$. Concurrent with increases in $\mathrm{Na}$ were increases in 24-h urinary $\mathrm{K}$ excretion as well as the urinary Na:K ratio. Among 8-12-year-old children, EI and the amount of food and beverages consumed on the day of the 24-h diet recall increased across tertiles of $\mathrm{Na}$ intake.

\section{Association between 24-h urinary sodium excretion and measures of adiposity}

Across the whole sample, there was a positive association between 24-h urinary $\mathrm{Na}$ excretion and BMI $z$ score. An additional $17 \mathrm{mmol} / \mathrm{d}$ of $\mathrm{Na}(1 \mathrm{~g}$ salt/d) was associated with a $0 \cdot 10$ higher BMI $z$ score, and $\mathrm{Na}$ intake accounted for $7 \%$ of the variance in BMI $z$ score. The association remained after adjustment for age, sex and SES (Table 3). When stratified by age group, the positive association remained in both age groups. In 8-12-year-old children the association remained after adjustment for energy and SSB intake.

Results from logistic regression analysis showed that a higher $\mathrm{Na}$ intake was associated with increased risk of being overweight or obese. Including all participants and with adjustment of confounders a $1 \mathrm{~g} / \mathrm{d}$ higher salt intake was associated with a $23 \%$ increase in the odds of being overweight or obese (Table 4). The association remained in age-stratified models and independent of energy and SSB intake in 8-12-year-old children.

Including all participants, $\mathrm{Na}$ intake was positively associated with abdominal obesity (Table 5). After adjustment for age, sex and SES an additional $1 \mathrm{~g} / \mathrm{d}$ of salt was associated with a $15 \%$ increase in the risk of being centrally obese. In age-stratified models, the positive association remained. In all models, the association between salt intake and abdominal obesity was not independent of BMI $z$ score.

\section{Discussion}

Among primary schoolchildren we found that 24-h urinary $\mathrm{Na}$ excretion was associated with a higher BMI $z$ score, greater risk of overweight/obesity and abdominal obesity. Of note the association between $\mathrm{Na}$ and abdominal obesity was not independent of BMI $z$ score, suggesting that the potential adipogenic effect of $\mathrm{Na}$ relates to total body weight and is not specific to central fat distribution. Overall associations were consistent across stratified age groups; however, the magnitude of the association was greatest in the 4-7-year-olds on all three adiposity outcome measures. Some caution should be applied when interpreting the findings in the 4-7-year-old children because of the small number of children classified as centrally obese ( $n$ 24) and overweight/obese ( $n$ 14).

The magnitude of the effect of $1 \mathrm{~g} / \mathrm{d}$ of salt on BMI $z$ score is small (i.e. $0 \cdot 10$ ), and the potential health significance of this is unclear. In obese children a reduction of at least 0.5 in BMI $z$ score is needed to achieve reductions in waist circumference, body fat and cardiovascular risk ${ }^{(32)}$. However, given intensive obesity lifestyle interventions report changes of only $-0 \cdot 10$ in BMI $z$ score $^{(33)}$, our finding for an effect of $\mathrm{Na}$ alone is not 

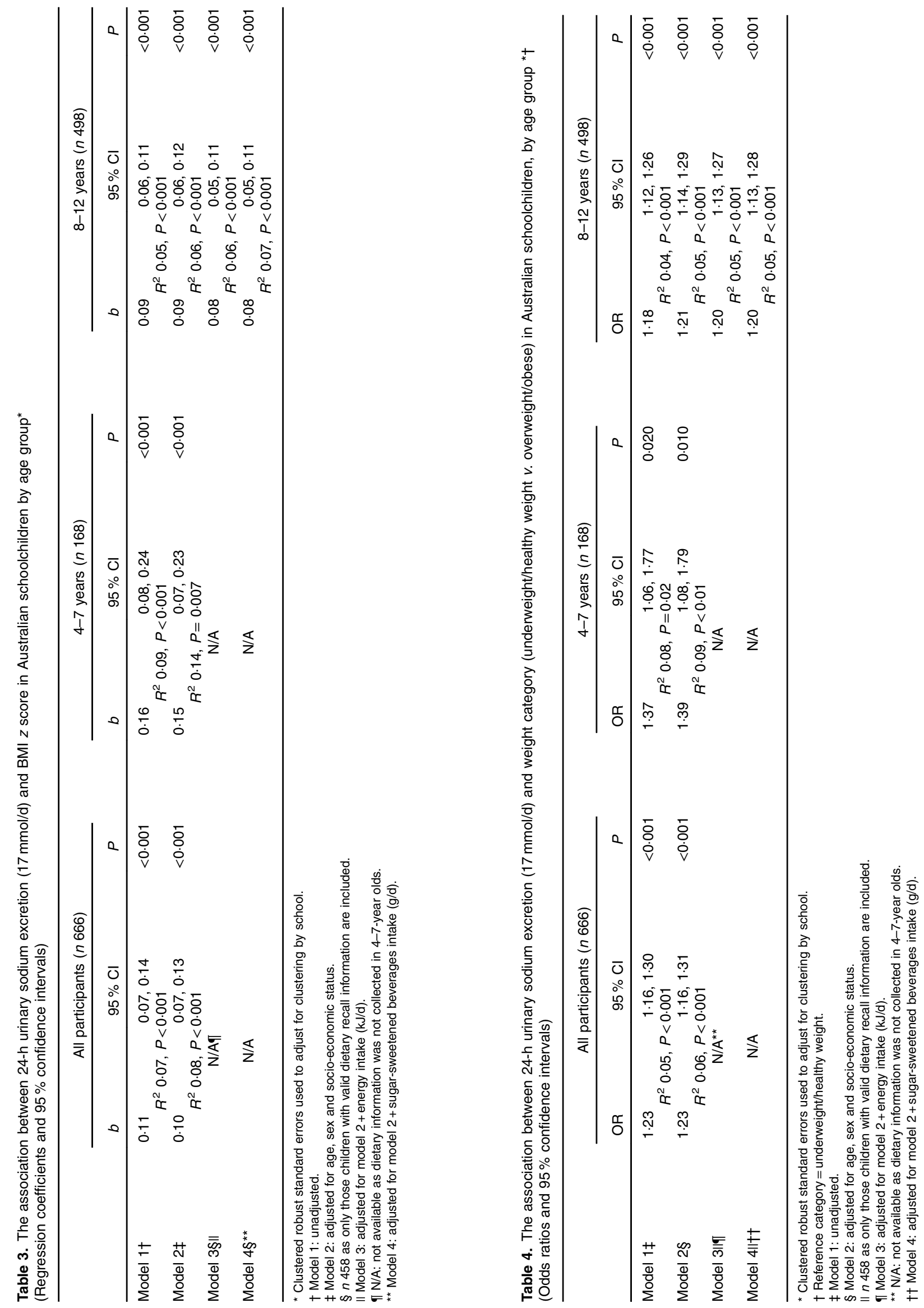


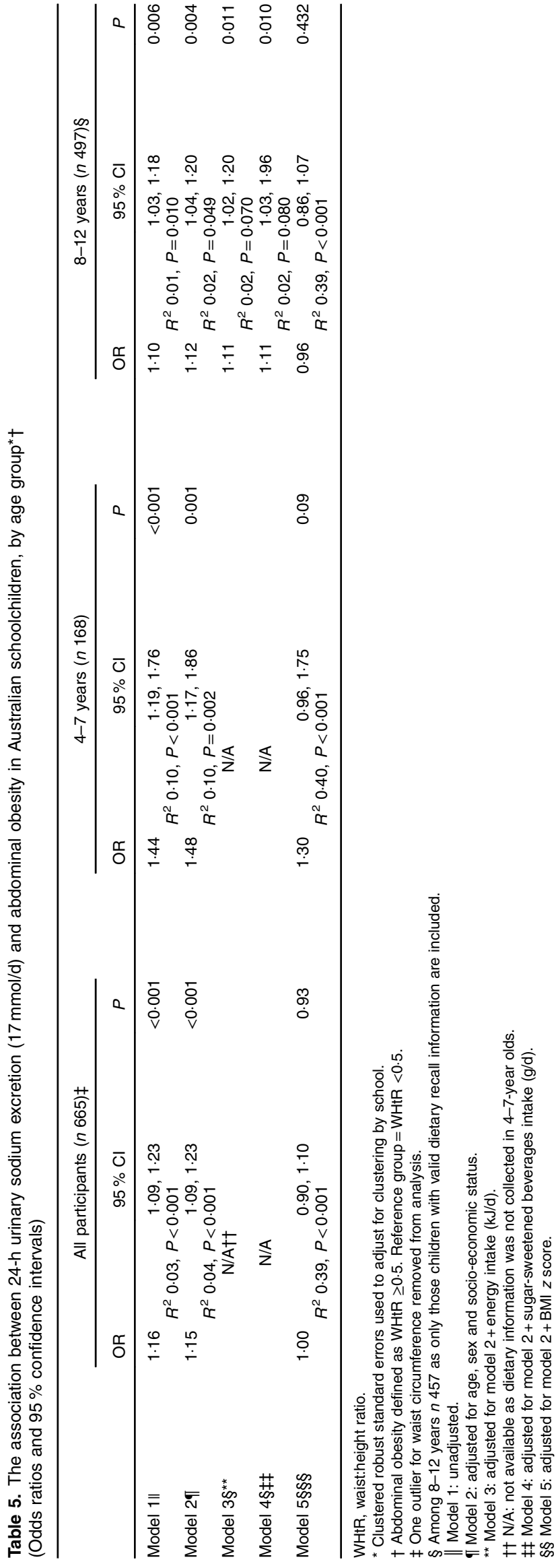

unexpected. A change of this magnitude may still be important at the population level and in slowing down the trajectory of excess weight gain during childhood. The variance in BMI $z$ score and weight status explained by $\mathrm{Na}$ intake alone was 7 and 5\%, respectively. Given the large number of determinants for childhood obesity, this level of variance explained by a single nutrient is notable. Comparatively sweetened beverages, which are often targeted in childhood obesity efforts, explained only $1 \%$ of the variance in body weight status among US children ${ }^{(34)}$.

Overall our findings are consistent with previous studies conducted in children ${ }^{(6-8,35)}$ as well as adults ${ }^{(7,35-39)}$. For example, in a large representative sample of Korean children aged 7-18 years participants in the highest quintile for $\mathrm{Na}$ density, as determined by 24 -h dietary recall, were 1.78 (95\% CI $1 \cdot 13,2 \cdot 80$ ) and $2 \cdot 13$ times (95\% CI $1 \cdot 16,3.91)$ more likely to be obese or centrally obese, respectively ${ }^{(7)}$. Unlike our study, the authors did not adjust for BMI $z$ score in the Na and abdominal obesity model; hence, it is unclear whether this association was independent of overall body size. Similarly in US adolescents, after adjustment for important confounders including energy, $\mathrm{Na}$ intake assessed by repeated 24-h dietary recalls was positively associated with BMI, waist circumference and fat mass $^{(8)}$. In contrast, among Canadian schoolchildren no difference in $\mathrm{Na}$ intake, as assessed by a web-based $24 \mathrm{~h}$ recall, across weight categories was found ${ }^{(40)}$. In adults, a positive association between $\mathrm{Na}$ intake, from 24-h dietary recall methods, and BMI was reported in nationally representative samples in the $\mathrm{USA}^{(38)}$ and Korea ${ }^{(7)}$.

Only one longitudinal paediatric study has assessed the association between 24 -h urinary $\mathrm{Na}$ and obesity risk ${ }^{(41)}$. In this study of German children aged 3-18 years positive baseline associations between $\mathrm{Na}$ intake and BMI $z$ score and \%BF were reported; however, there was limited evidence for a temporal relationship. Specifically, in the unadjusted model, baseline $\mathrm{Na}$ was associated with an increase in \%BF; however, in adjusted models this was only a trend $(P=0 \cdot 073)$. Conversely there was no association between baseline $\mathrm{Na}$ and change in BMI $z$ score. Similarly, there was no association between change in $\mathrm{Na}$ and change in either BMI $z$ score or \%BF. In adults, in a Danish longitudinal cohort with 6 years of follow-up, higher 24-h urinary $\mathrm{Na}$ excretion was associated with increased body fat and decreased fat-free mass, but not with body weight or waist circumference $^{(41)}$; however, the positive associations were observed only in adjusted models.

There are several mechanisms that may explain the relationship between $\mathrm{Na}$ intake and obesity risk. First, as $\mathrm{Na}$

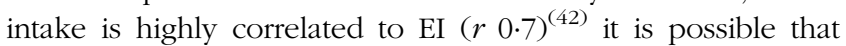
overall greater consumption of foods that are high in both energy and $\mathrm{Na}$ promotes weight gain. Likewise, foods that contain higher levels of salt may enhance the palatability of foods, which are also high in fat and energy. In addition, through the effects of $\mathrm{Na}$ on thirst, a salty diet may encourage greater consumption of high-energy SSB when these are readily available ${ }^{(3-5)}$. Given that increased EI is a plausible factor that may link Na to obesity risk, we adjusted for both energy and SSB intake in the subsample of children with dietary data. Consistent with others ${ }^{(6-8,38)}$, we found that the association 
between $\mathrm{Na}$ intake and BMI $z$ score and weight category was independent of energy and SSB intake, suggesting other mechanisms may be at play. However, an important consideration within our study is that we found no association between EI and BMI $z$ score or weight status (data not shown), and the association between 24-h urinary $\mathrm{Na}$ and EI was very weak ( $r 0 \cdot 10, P=0 \cdot 03$ ). Therefore, it is not surprising that the additional adjustment for energy or SSB intake did not alter our results. It is possible that, because of limitations associated with 24-h dietary recall methods - for example, estimating portion size and memory bias ${ }^{(26)}$ - the degree of error in our measure of EI is large. Comparatively, a urinary biomarker is not subject to these limitations. In adults important differences in relation to the assessment method of $\mathrm{Na}$ and the relationship to BMI have previously been reported ${ }^{(43)}$. In this large study of adults who completed both a $24-\mathrm{h}$ diet recall and $24 \mathrm{~h}$ urine collection, it was shown that 24-h dietary recall $\mathrm{Na}$ was inversely associated with BMI, yet conversely 24-h urinary $\mathrm{Na}$ was positively associated with $\mathrm{BMI}^{(43)}$. This emphasises important differences between the two methodologies.

It may be that the objective measure of 24-h urinary $\mathrm{Na}$ acts as a surrogate marker for overall poorer diet quality ${ }^{(36)}$, which in turn is linked to obesity risk. In 6-year-old Danish children greater diet quality was associated with lower 24-h urinary $\mathrm{Na}$ excretion and higher 24-h urinary $\mathrm{K}$ excretion ${ }^{(44)}$. Our finding whereby the urinary $\mathrm{Na}: \mathrm{K}$ ratio concurrently increased across tertiles of urinary $\mathrm{Na}$ lends some support to the notion that overall diet quality may be an important factor in explaining the $\mathrm{Na}$ and obesity relationship.

Alternatively it has been suggested that $\mathrm{Na}$ may influence the formation of adipocyte tissue via increased lipogenic activity $^{(45,46)}$. In rats, those fed a high-Na diet, compared with those fed a normal-Na diet, had a greater increase in adipocyte mass despite the same amount of overall food being consumed. In addition, rats fed the high-Na diet displayed greater uptake of glucose and conversion into lipids within adipocyte tissue ${ }^{(45)}$. Whether higher salt intake in humans has a similar effect on glucose metabolism is unknown. In adults it has been shown that higher 24-h urinary $\mathrm{Na}$ excretion is associated with the metabolic syndrome ${ }^{(47,48)}$, including abdominal obesity; however, neither of these studies adjusted for EI.

Limitations of the present study include the cross-sectional design, convenience sample and the low response rate, which limits the generalisability of the findings to the wider population. Compared with the Australian population our sample contained fewer overweight and obese children ${ }^{(49)}$. We had no dietary data for children aged 4-7 years and were unable to determine whether the associations between $\mathrm{Na}$ and adiposity outcomes were independent of energy. Furthermore, the collection of dietary data and urine samples was not concurrent and there may have been a positive association between EI and BMI that we were unable to detect. The major strength of this study is the use of a urinary biomarker to assess $\mathrm{Na}$ intake, removing potential bias from mis-reporting, a behaviour frequently observed in dietary studies ${ }^{(26)}$; further, this method captures $\mathrm{Na}$ from food sources as well as discretionary salt use.

In conclusion, our study is in agreement with previous findings indicating a cross-sectional positive association between
$\mathrm{Na}$ intake and measures of adiposity in Australian schoolchildren. A greater understanding of the potential mechanistic action is required in conjunction with longitudinal studies.

\section{Acknowledgements}

The authors acknowledge the Victorian Department of Early Childhood and Development for their support in allowing the study to be conducted within the government school sector. The authors thank all schools and children who participated in the study.

This study was funded by a National Heart Foundation of Australia Grant-in-Aid (G 10M 5021) and a Helen MacPherson Smith Trust Fund Project Grant (6002). At the time of this work C. A. G. was supported by a National Heart Foundation of Australia Postgraduate Scholarship (PP 08M 4074); C. A. G. is currently supported by a National Heart Foundation of Australia Postdoctoral Fellowship (Award ID: 100155). None of the funders had any role in the design, analysis or writing of this article.

C. A. G., L. J. R., K. J. C. and F. J. H. designed the research. C. A. G. analysed the data and drafted the manuscript. L. J. R., K. J. C., F. J. H. and C. A. N. secured project funding and reviewed and revised the manuscript. All authors approved the final manuscript as submitted.

The authors declare that there are no conflicts of interest.

\section{References}

1. Brown IJ, Tzoulaki I, Candeias V, et al. (2009) Salt intakes around the world: implications for public health. Int J Epidemiol 38, 791-813.

2. He FJ \& MacGregor GA (2006) Importance of salt in determining blood pressure in children meta-analysis of controlled trials. Hypertension 48, 861-869.

3. Grimes CA, Riddell LJ, Campbell KJ, et al. (2013) Dietary salt intake, sugar-sweetened beverage consumption, and obesity risk. Pediatrics 131, 14-21.

4. Grimes CA, Wright JD, Liu K, et al. (2013) Dietary sodium intake is associated with total fluid and sugar-sweetened beverage consumption in US children and adolescents aged 2-18 y: NHANES 2005-2008. Am J Clin Nutr 98, 189-196.

5. He FJ, Marrero NM \& MacGregor GA (2008) Salt intake is related to soft drink consumption in children and adolescents: a link to obesity? Hypertension 51, 629-634.

6. Libuda L, Kersting M \& Alexy U (2012) Consumption of dietary salt measured by urinary sodium excretion and its associated with body weight status in healthy children and adolescents. Public Health Nutr 15, 433-441.

7. Yoon YS \& Oh SW (2013) Sodium density and obesity: the Korea National Health and Nutrition Examination Survey 2007-2010. Eur J Clin Nutr 67, 141-146.

8. Zhu H, Pollock N, Kotak I, et al. (2014) Dietary sodium, adiposity, and inflammation in healthy adolescents. Pediatrics 133, e635-e642.

9. Karppanen H \& Mervaala E (2006) Sodium intake and hypertension. Prog Cardiovasc Dis 49, 59-75.

10. Hu F (2013) Resolved: there is sufficient scientific evidence that decreasing sugar-sweetened beverage consumption will reduce the prevalence of obesity and obesity-related diseases. Obes Rev 14, 606-619. 
11. Stricker EM, Hoffmann ML, Riccardi CJ, et al. (2003) Increased water intake by rats maintained on high $\mathrm{NaCl}$ diet: analysis of ingestive behaviour. Physiol Behav 79, 621-631.

12. He FJ, Markandu ND, Sagnella GA, et al. (2001) Effect of salt intake on renal excretion of water in humans. Hypertension 38, 317-320.

13. Stachenfeld NS (2008) Acute effects of sodium ingestion on thirst and cardiovascular function. Curr Sports Med Rep 7, S7-S13.

14. Espeland MA, Kumanyika S, Wilson AC, et al. (2001) Statistical issues in analysing 24-hour dietary recall and 24-hour urine collection data for sodium and potassium intakes. $\mathrm{Am} J$ Epidemiol 153, 996-1006.

15. Singh AS, Mulder C, Twisk JWR, et al. (2008) Tracking of childhood overweight into adulthood: a systematic review of the literature. Obes Rev 9, 474-488.

16. Grimes CA, Baxter JR, Campbell KJ, et al. (2015) Crosssectional study of 24-hour urinary electrolyte excretion and associated health outcomes in a convenience sample of Australian primary schoolchildren: the Salt and Other Nutrients in Children (SONIC) Study Protocol. JMIR Res Protoc 4, e7.

17. Australian Bureau of Statistics (2013) Socio-Economic Indexes for Areas. http://www.abs.gov.au/websitedbs/censushome. nsf/home/seifa (accessed December 2014).

18. Jaffe M (1886) Uber den Niederschlag, welchen Pikrinsäure im normalen Harn erzeugt, und über eine neue Reaction des Kreatinins (Precipitation, which generates picric acid in normal urine, and a new reaction of creatinine). $Z$ Physiol Chem 10, 391-400.

19. Institute of Medicine (2004) Dietary Reference Intakes for Water, Potassium, Sodium, Chloride and Sulfate. Washington, DC: The National Academies Press

20. Flegal K \& Cole T (2013) Construction of LMS parameters for the Centers for Disease Control and Prevention 2000 growth charts. Natl Health Stat Report 63, 1-3.

21. Kuczmarski RJ, Ogden CL, Guo SS, et al. (2002) 2000 CDC growth charts for the United States: methods and development. Vital Health Stat 11, 1-190.

22. Cole TJ (2000) Establishing a standard definition for child overweight and obesity worldwide: international survey. BMJ 320, 1-6.

23. Cole TJ, Flegal KM, Nicholls D, et al. (2007) Body mass index cut offs to define thinness in children and adolescents: international survey. BMJ 335, 194-197.

24. Garnett SP, Baur LA \& Cowell CT (2008) Waist-to-height ratio: a simple option for determining excess central adiposity in young people. Int J Obes (Lond) 32, 1028-1030.

25. Kahn HS, El ghormli L, Jago R, et al. (2014) Cardiometabolic risk assessments by body mass index z-score or waistto-height ratio in a multiethnic sample of sixth-graders. J Obes 2014, 421658.

26. Livingstone MB, Robson PJ \& Wallace JM (2004) Issues in dietary intake assessment of children and adolescents. $\mathrm{Br} J$ Nutr 92, Suppl. 2, S213-S222.

27. Sichert-Hellert W, Kersting M \& Schoch G (1998) Underreporting of energy intake in 1 to 18 year old German children and adolescents. $Z$ Ernahrungswiss 37, 242-251.

28. Goldberg GR, Black AE, Jebb SA, et al. (1991) Critical evaluation of energy intake data using fundamental principles of energy physiology: 1 . Derivaton of cut-off limits to identify under-recording. Eur J Clin Nutr 45, 569-581.

29. Torun B, Davies PS, Livingstone MB, et al. (1996) Energy requirements and dietary energy recommendations for children and adolescents 1 to 18 years old. Eur J Clin Nutr $\mathbf{5 0}$, Suppl. 1, S37-S80; discussion S-1.

30. Black AE (2000) Critical evaluation of energy intake using the Goldberg cut-off for energy intake: basal metabolic rate.
A practical guide to its calculation, use and limitations. Int I Obes Relat Metab Disord 24, 1119-1130.

31. Magarey A, Watson J, Golley RK, et al. (2011) Assessing dietary intake in children and adolescents: considerations and recommendations for obesity research. Int J Pediatr Obes $\mathbf{6}$, 2-11.

32. Ford AL., Hunt LP., Cooper A., et al. (2010) What reduction in BMI SDS is required in obese adolescents to improve body composition and cardiometabolic health? Arch Dis Child 95. 256-261.

33. Ho M, Garnett SP, Baur L, et al. (2012) Effectiveness of lifestyle interventions in child obesity: systematic review with metaanalysis. Pediatrics 130, e1647-e1671.

34. Nicklas TA, Yang SJ, Baranowski T, et al. (2003) Eating patterns and obesity in children. The Bogalusa Heart Study. Am J Prev Med 25, 9-16.

35. Ma Y, He FJ \& MacGregor GA (2015) High salt intake: independent risk factor for obesity? Hypertension 66, 843-849.

36. Navia B, Aparicio A, Perea JM, et al. (2014) Sodium intake may promote weight gain; results of the FANPE study in a representative sample of the adult Spanish population. Nutr Hosp 29, 1283-1289.

37. Song H, Cho Y \& Lee H-J (2013) Dietary sodium intake and prevalence of overweight in adults. Metabolism 62, 703-708.

38. Yi SS, Firestone MJ \& Beasley JM (2015) Independent associations of sodium intake with measures of body size and predictive body fatness. Obesity 23, 20-23.

39. Yi SS \& Kansagra SM (2014) Associations of sodium intake with obesity, body mass index, waist circumference, and weight. Am J Prev Med 46, e53-e55.

40. Woodruff SJ., Fryer K., Campbell T., et al. (2014) Associations among blood pressure, salt consumption and body weight status of students from south-western Ontario. Public Health Nutr 17, 1114-1119.

41. Larsen SC, Angquist L, Sorensen TI, et al. (2013) 24h urinary sodium excretion and subsequent change in weight, waist circumference and body composition. PLOS ONE 8, e69689.

42. Willet W (2013) Nutritional Epidemiology. New York, NY: Oxford University Press.

43. Zhang J, Temme EH, Sasaki S, et al. (2000) Under- and overreporting of energy intake using urinary cations as biomarkers: relation to body mass index. Am J Epidemiol $\mathbf{1 5 2}$, 453-462.

44. Kristbjornsdottir OK, Halldorsson TI, Thorsdottir I, et al. (2012) Association between 24-hour urine sodium and potassium excretion and diet quality in six-year-old children: a cross sectional study. Nutr J 11, 94.

45. Fonseca-Alaniz MH, Brito LC, Borges-Silva CN, et al. (2007) High dietary sodium intake increases white adipose tissue mass and plasma leptin in rats. Obesity 15, 2200-2208.

46. Fonseca-Alaniz MH, Takada J, Andreotti S, et al. (2008) High sodium intake enhances insulin-stimulated glucose uptake in rat epididymal adipose tissue. Obesity 16, $1186-1192$

47. Ge Z, Guo X, Chen X, et al. (2015) Association between $24 \mathrm{~h}$ urinary sodium and potassium excretion and the metabolic syndrome in Chinese adults: the Shandong and Ministry of Health Action on Salt and Hypertension (SMASH) study. Br J Nutr 113, 996-1002.

48. Hoffmann IS \& Cubeddu LX (2009) Salt and the metabolic syndrome. Nutr Metab Cardiovasc Dis 19, 123-128.

49. Australian Bureau of Statistics (2013) 4364.0.55.003 - Australian Health Survey: updated results, 2011-2012. http://www. abs.gov.au/ausstats/abs@.nsf/Lookup/33C64022ABB5ECD5 CA257B8200179437?opendocument (accessed 2015). 